\title{
Description and evaluation of imposex in Strombus canarium Linnaeus, 1758 (Gastropoda, Strombidae): A potential bio-indicator of tributyltin pollution.
}

\begin{abstract}
Strombus canarium Linnaeus, 1758 is an important gastropod species within the study area and was traditionally collected for food by the locals. The objective of the present study is to assess the incidence of imposex and its severity in this species. Adult conchs were sampled during their main reproductive period, from October 2005 to January 2006, at Sungai Pulai estuary, Johor Straits, Malaysia. A total of $32.81 \%$ of adult females showed imposex characteristics, with varying degrees of severity though. The relative penis size (RPS) index ranged from 1.74 to 33.29 (mean $=13.40 \pm 2.27, \mathrm{n}=21)$, while the relative penis length (RPL) index ranged from 6.28 to 55.19 (mean $=25.83 \pm 3.33, \mathrm{n}=21$ ). The use of vas deferens sequence (VDS) index was however cannot be applied as the presence of egg groove obscured any vas deferens development in affected females. Sequence of imposex (male penis) development in female conch, from merely a small stump to an advance male penis homologous was therefore carefully analyzed and described, and an alternative imposex classification scheme was proposed. S. canarium can be a good indicator for monitoring of organotin pollution within the study area. However, more studies are needed in order to further develop and test its validity and application, such as its correlation with levels of pollutant within the tissues and the environment, as well as its application on other Strombus species.
\end{abstract}

Keyword: Dog conch; Relative penis length (RPL); Relative penis size (RPS); Imposex scheme; Strombidae. 